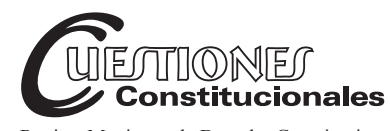

Revista Mexicana de Derecho Constitucional Núm. 43, julio-diciembre 2020

\title{
Límites a la responsabilidad patrimonial por daño moral
}

\author{
Limits to patrimonial liability for moral damage
}

\section{Oscar Antonio LEÓN OYOSA*}

RESUMEN: A partir del 14 de junio de 2002 la responsabilidad patrimonial del Estado en México no solamente fue elevada a categoría constitucional, sino que fue introducida con carácter objetivo y directo; esto es, para hacerla valer es necesario demostrar que se ha sufrido daño en la esfera jurídica del cual no se tiene el deber jurídico de soportar, sin necesidad de acreditar previamente el actuar ilícito del servidor público que lo causó, pues bajo esta figura el Estado es directamente responsable de los daños causados por sus agentes. Sin embargo, la redacción del texto constitucional cedió al legislador ordinario la imposición de límites a las indemnizaciones derivadas de la responsabilidad patrimonial, mismas que aquél estableció en la Ley Federal de Responsabilidad Patrimonial del Estado, publicada el 31 de diciembre de 2004 en el Diario Oficial de la Federación. Precisamente, tales límites serán motivo de análisis en el presente, con la finalidad de identificar si son constitucionales, o por el contrario, se apartan del fin buscado por la norma fundamental. De igual manera, se valorará la redac-
ABSTRACT: Since 14, 2002, the State's property liability in Mexico was not only elevated to a constitutional category, but was introduced with an objective and direct character, so, it's necessary to demonstrate that it has suffered in the legal sphere Which does not have the legal duty to support, without having to previously accredit the illicit action of the public servant who caused the damage, because under this figure the State is directly responsible for the damages caused by its agents. However, the wording of the constitutional text gave the ordinary legislator the imposition of limits on the indemnities derived from the patrimonial responsibility, which the same established in the Federal Law of Asset Liability of the State published on December 31, 2004 in the Official Gazette of The Federation. Precisely these limits will be the subject of analysis in the present, in order to identify whether they are constitutional, or on the contrary depart from the end sought by the Fundamental Standard. Likewise, the wording of the constitutional

* Maestro en Estudios (PNPC) por la Universidad Juárez Autónoma de Tabasco; estudiante del doctorado en Estudios Jurídicos (PNPC) impartido en la Universidad Juárez Autónoma de Tabasco. México. ORCID: 0000-0001-8178-4115. Correo electrónico: leon.oyosa@gmail.com. 
ción del texto constitucional con relación a las justificaciones para la imposición de límites respecto del daño moral.

Palabras clave: responsabilidad patrimonial, límites, daño moral. text in relation to the justifications for the imposition of limits, especially when dealing with moral damages, will be evaluated.

Keywords: asset liability, limits, moral damage.

\begin{abstract}
SUMARIO: I. Introducción. II. Definición de daño moral y alcance de las reparaciones conforme a la Convención Americana sobre Derechos Humanos. III. Limites a la indemnización por daño moral. IV. Pronunciamiento de la Suprema Corte: los límites previstos en la indemnización por daño moral son inconstitucionales. V. Límites idóneos para restringir reclamos injustificados. VI. Motivaciones para limitar las indemnizaciones en materia de responsabilidad patrimonial. VII. Análisis del voto disidente del ministro Gudiño Pelayo en el amparo en revisión 75/2009. VIII. Propuesta: pregunta lógico-jurídica para arribar a la conclusión de una indemnización justa por daño moral. IX. Criterios recientes de la Suprema Corte de Justicia de la Nación. X. Propuestas iniciales versus texto constitucional vigente. XI. Presunción del daño moral en el Consejo de Estado de Colombia. XII. Conclusiones. XIII. Bibliografía.
\end{abstract}

\title{
I. INTRODUCCIÓN
}

Sin duda alguna, el jurista Álvaro Castro Estrada ha sido uno de los principales impulsores de la inclusión de la institución de responsabilidad patrimonial a nivel constitucional en el Estado mexicano - con los elementos característicos que identifican la evolución de este principio en el nuevo régimen estatal—, ${ }^{1}$ logrando el aporte de la integración de un régimen de

1 El surgimiento del denominado Estado moderno en los siglos XVI y XVII consistió fundamentalmente en un fenómeno de concentración de poder por parte del rey. La evolución derivada de la concentración del poder llevó a excesos, que al paso de dos siglos intentaron corregirse con la Revolución francesa y el surgimiento del nuevo régimen. El nuevo régimen se construyó con base en dos grandes principios: el de legalidad y el de responsabilidad patrimonial del Estado, ambos destinados a limitar el ejercicio monopólico, y en ocasiones abusivo, del poder, en un sistema que ya no regresó a la descentralización propia del del antiguo régimen. Lozano Díez, José Antonio, "Límites

Esta obra está bajo una Licencia Creative Commons

Atribución-NoComercial-SinDerivar 4.0 Internacional, IIJ-UNAM. 
responsabilidad general, objetivo y directo. ${ }^{2}$ Así, la primera propuesta que desde la jurisprudencia dogmática hiciera el autor en noviembre de 1997, origen de la actual garantía constitucional, fue redactada en los términos siguientes:

Artículo $113 \ldots$ Todo aquel que sufra una lesión en sus bienes y derechos, con motivo de la actividad del Estado, tendrá derecho a ser indemnizado en forma proporcional y equitativa, conforme a lo dipuesto por las leyes que al efecto expidan el Congreso de la Unión y las Legislaturas de los Estados dentro del ámbito de sus respectivas competencias. Los tribunales contencioso-administrativos serán los competentes para conocer de las controversias derivadas de la aplicación de las mismas. ${ }^{3}$

Tal propuesta sufrió diversas modificaciones hasta el texto aprobado mediante la reforma constitucional del 14 de junio de 2002, publicada en el Diario Oficial de la Federación. Sin embargo, cabe destacar que la iniciativa promovida el 22 de abril de 1999 por el Partido Revolucionario Institucional, fiel al texto del jurista de mérito, incluyó la proporcionalidad y equidad en la indemnización; a su vez, la diversa promovida por el Partido Acción Nacional el 19 de junio de ese mismo año previó la equidad en la indemnización por los daños y perjuicios ocasionados por la actividad de la Federación.

Fue con la iniciativa propuesta el 14 de abril de 2000 por la Consejería Jurídica del Ejecutivo Federal, que respecto de la indemnización sería conforme a "las bases, límites y procedimientos que establecieran las leyes"; modificación tal que inclusive fue respaldada por Castro Estrada en su nueva sugerencia de redacción del 18 de abril de $2000 .^{4}$

No cade duda que las iniciativas de reforma presentadas a partir del 19 de junio de 1999 tuvieron el aserto de incluir la figura de la responsabilidad objetiva y directa, lo que siginificó un gran logro y avance en el sistema

presupuestarios a la responsabilidad patrimonial del Estado en el sistema jurídico mexicano", en Rodriguez-Arana Muñoz, Jaime et al. (coords.), La responsabilidad patrimonial de la administración pública, México, Espress, 2014, t. I, pp. 15-24.

2 Castro Estrada, Álvaro, Responsabilidad patrimonial del Estado, México, Porrúa, 2006, p. XXIII.

3 Acosta García, Cristian Miguel, Responsabilidad patrimonial del estado. Teoría y casos prácticos, México, Novum, p. 150.

4 Ibidem, pp. 151-154. 
jurídico mexicano. No obstante la plausibilidad de ello, resulta necesario analizar la conveniencia o no, que a tal garantía, en propuestas iniciales, se incluyera una indemnización proporcional y equitativa, para modificarla posteriormente, por una indemnización "conforme a las bases, límites y procedimientos que establecieran las leyes"; sobre todo, en atención a los límites respecto del daño moral, impuestos por el legislador ordinario en la Ley Federal de Responsabilidad Patrimonial del Estado (LFRPE), y sobre los cuales la Suprema Corte de Justicia de la Nación se ha pronunciado por su inconstitucionalidad, que será motivo de análisis en el presente, en que abordamos su trascendencia y las implicaciones que el texto declarado inconstitucional continúe vigente.

\section{DEFINICIÓN DE DAÑO MORAL Y ALCANCE \\ DE LAS REPARACIONES CONFORME A LA CONVENCIÓN AMERICANA SOBRE DERECHOS HUMANOS}

El daño moral se vincula a la afectación espiritual de la persona a través de la lesión de los derechos de la personalidad, entendiendo por ello una categoría especial de derechos subjetivos que, fundados en la dignidad de la persona, garantiza el goce y respeto de su propia identidad e integridad en todas las manifestaciones físicas y propias del intelecto de esa persona. ${ }^{5}$

En lo tocante a la reparación por daños causados por el Estado, el concepto de reparación integral derivado del artículo 63.1 de la Convención Americana sobre Derechos Humanos, abarca la acreditación de daños en la esfera material e inmaterial y el otorgamiento de medidas tales como: a) la investigación de los hechos; b) la restitución de derechos, bienes y libertades; c) la rehabilitación física, psicológica o social; d) la satisfacción, mediante actos en beneficio de las víctimas; e) las garantías de no repetición de las violaciones, y f) la indemnización compensatoria por daño material e inmaterial. A través de esta facultad, la Corte Interamericana de Derechos Humanos (Corte IDH) ha ordenado medidas emblemáticas para muchos países de la región, que han colaborado en la consolidación del Estado de derecho y la vigencia de los derechos humanos. Dichas medi-

5 Pérez Fuentes, Gisela María, "Responsabilidad por daños a la persona: daño moral”, en Pérez Fuentes, Gisela María (coord.), Temas actuales de responsabilidad civil, México, Tirant lo Blanch, 2018, pp. 99-149. 
das en su dimensión individual han beneficiado a miles de personas en la región (a través de otorgamiento de becas educativas, atención médica y psicológica, actos de conmemoración, búsqueda de desaparecidos, y compensaciones económicas). La jurisprudencia de la Corte Interamericana al respecto, constituye uno de los avances más importantes en el desarrollo internacional de la reparación integral. ${ }^{6}$

De igual forma, el derecho moderno de daños pone énfasis en la protección a los derecho fundamentales, y así, la doctora Pérez, retomando los Criterios de la Corte Interamericana, precisa que el daño causado es el que determina la indemnización, y se caracteriza por:

a) El derecho a una reparación integral o justa indemnización, derecho sustantivo cuya extensión debe tutelarse en favor de los gobernados. c) El derecho moderno de daños mira a la naturaleza y extensión del daño, a las víctimas y no a los victimarios. Así su naturaleza y su monto dependen del daño ocasionado, de manera que las reparaciones no pueden implicar ni enriquecimiento ni empobrecimiento para la víctima o sus sucesores. d) Dicho derecho no debe restringirse en forma innecesaria. Se pretende que la responsabilidad no sea excesiva, ya que debe subordinarse a requisitos cualitativos. e) Una indemnización no es justa cuando se limita con topes o tarifas, cuando en lugar de ser el juez quien la cuantifique con base en criterios de razonabilidad, es el legislador quien, arbitrariamente, fija montos indemnizatorios, al margen del caso y su realidad. Sólo el juez, que conoce las particularidades del caso, puede cuantificar la indemnización con justicia y equidad.?

En el caso El Amparo vs. Venezuela, la Corte IDH argumentó que aun cuando una sentencia condenatoria puede constituir en sí misma una forma de reparación y satisfacción moral, en el caso en estudio no sería suficiente dada la específica gravedad de la violación al derecho a la vida y al sufrimiento moral causado a las víctimas y sus familias, que deben ser indemnizadas conforme a la equidad. ${ }^{8}$

6 Calderón Gamboa, Jorge F., "La reparación integral en la jurisprudencia de la Corte Interamericana de Derechos Humanos: estándares aplicables al nuevo paradigma mexicano", en Ferrer Mac-Gregor Poisot, Eduardo, Derechos humanos en la Constitución: comentarios de jurisprudencia constitucional e interamericana, México, Suprema Corte de Justicia de la Nación-UNAM-Fundación Konrad Adenauer, 2013, t. I, pp. 145-219.

7 Pérez Fuentes, Gisela María, op. cit., pp. 22 y 23.

8 Steiner, Christian y Uribe, Patricia, Convención Americana sobre Derechos Humanos comentada, México, Suprema Corte de Justicia de la Nación, p. 863. 
De lo anterior entendemos que si bien en el caso resuelto por la Corte IDH la sentencia no constituía una forma de reparación y satisfacción moral, pueden existir casos en que la sola sentencia sea suficiente para reparar el daño moral, claro está, ello depende de la gravedad de la violación, a lo que sumaríamos la particularidad de cada caso; es decir, no sería suficiente el criterio en el siguiente sentido "si el caso no reviste gravedad, será suficiente la sentencia condenatoria para repararlo", dado que, precisamente por la particularidad de cada asunto, habrá casos en que sea suficiente la sentencia condenatoria, y casos en los que el Estado deberá desplegar otro tipo de acciones para que la reparación moral sea completa, aunque la violación no sea grave.

La Corte ha evolucionado en su interpretación de qué comprende el daño moral, y ha modificado las exigencias que establece para reconocer las formas de padecimiento que deben ser indemnizadas; y en muchos casos presume la existencia de daños con base en la constatación de las violaciones. ${ }^{9}$ Esto último es de destacar con relación al principio pro homi$n e, \mathrm{y}$ hacemos mención especial, atendiendo a la complejidad que implica la demostración del daño moral, dada la subjetividad que entraña, por lo que consideramos atinada la presunción del daño una vez constatadas las violaciones, con lo cual ha de brindarse la protección más amplia. ${ }^{10}$

Derivado de casos resueltos por la Corte Interamericana ${ }^{11}$ en lo que respecta a la reparación del daño moral tanto a las víctimas como a sus familiares, elaboramos la siguiente estructura a partir de la identificación de criterios sostenidos en dicha materia:

Sufrimiento padecido por la víctima y/o familiares directos de la víctima:

a) Disposición de pago a la víctima:

- Pago directo: se realiza directamente con relación al sufrimiento o padecimiento de la víctima, cuyo monto es superior si la víctima sigue con vida.

9 Ibidem, p. 864.

10 Claro está, como se señaló en líneas anteriores, esto será atendiendo a las particularidades y circunstancias del caso concreto, pues la presunción no se traduce en un cheque en blanco para reclamar indemnizaciones no debidas, sino para resituir en la justa medida la afectación sufrida por la víctima o sus allegados.

11 Caso Velázquez Rodríguez vs. Honduras; caso Aloeboetoe vs. Surinam; caso Garrido y Baigorria vs. Argentina; caso Loaiza Tamayo vs. Perú; caso Castillo Páez vs. Perú, y caso de "Los Niños de la Calle" (Villagrán Morales y otros) vs. Guatemala. 
- Pago por herencia a sus familiares: se realiza directamente en relación con el padecimiento de la víctima, cuando ésta ha fallecido o privada de la vida, y toda vez que en la indemnización por herencia los familiares que reciben no necesitan comprobar el sufrimiento ni el grado afectivo, pues reciben a nombre de la víctima y por las violaciones irrogadas; es distinto el monto indemnizatorio que hayan de recibir los familiares por el sufrimiento padecido por éstos al que reciben por suceder a la víctima en su padecimiento.

b) Disposición de pago a familiares de la víctima

- Por el sufrimiento causado por el vínculo familiar: en estos casos ha tomado en cuenta la relación afectiva y el grado de convivencia de la vícitma con el familiar, para determinar el monto indemnizatorio.

- Por ser miembros de una familia integrada: respecto a los hermanos a veces son incluidos dependiendo el grado de cercanía; sin embargo, en el caso Laoyza Tamayo tomó en consideración a padres, hijos y hermanos, argumentando que como miembros de una familia integrada no podían ser indiferentes a las graves aflicciones de la víctima.

Respecto al tema, concluimos con la siguiente reflexión: si la finalidad de la indemnización por daño moral consiste en restituir en la medida de lo posible a las personas afectadas en dicho rubro respecto de la víctima, en sus resoluciones la Corte debería, al menos, analizar el sufrimiento de los integrantes que conforman las nuevas estructuras familiares, las cuales, sin tener vínculos sanguíneos, se encuentran unidos por lazos afectivos y padecen sufrimientos cuando uno de sus miembros resulta afectado. ${ }^{12}$

12 En la actualidad, el concepto de familia presenta una transformación sustancial en atención a los nuevos modelos sociales en que ésa se desarrolla; ya no se considera integrada exclusivamente por los parientes y los cónyuges como tradicionalmente se les identificaba; es decir, vinculada por matrimonio y relaciones parentales; ahora y en atención a la dinámica social, se contemplan otras formas de relaciones humanas, donde los miembros que la integran se encuentran vinculados por lazos de afecto, de respeto, de convivencia y de solidaridad... Se deja entonces abierto el debate social que permita despejar el horizonte teórico, al concebir familias disímiles con integrantes de iguales o diferentes sexos, de iguales o diferentes orígenes territoriales, así como de la misma 


\section{LÍMITES A LA INDEMNIZACIÓN POR DAÑO MORAL}

El artículo 14 de la Ley Federal de Responsabilidad Patrimonial del Estado, ${ }^{13}$ en su fracción II, dispone que en el caso de daño moral, la autoridad administrativa o jurisdiccional calculará el monto de la indemnización de acuerdo con los criterios establecidos por el Código Civil Federal, pero no excederá del equivalente a 20,000 veces el salario mínimo general diario ${ }^{14}$ vigente en el Distrito Federal por cada reclamante afectado.

Tal disposición derivó de la libertad configurativa dispuesta en el artículo 113 constitucional, ${ }^{15}$ en la cual el monto resarcitorio por los daños ${ }^{16}$ causados por el Estado sería conforme a los límites establecidos por las leyes. Así, el legislador federal prescribió que no obstante conforme al Código Civil el monto de la indemnización se calcurá conforme a dicho ordenamiento y los dictámenes periciales ofrecidos por el reclamante, aquélla no excederá de la cantidad antes señalada.

proveniencia biológica o no, unidos formal o informalmente, incluyéndose en el núcleo social elementos familiares mixtos, como los que se integran en las llamadas familias amalgamadas. Oliva Gómez, Eduardo y Villa Guardiola, Vera Judith, "Hacia un concepto interdisciplinario de la familia en la globalización”, Justicia Juris, vol. 10, núm. 1, enerojunio de 2014, pp. 11-20.

13 Publicada en el Diario Oficial de la Federación el 31 de diciembre de 2004, última reforma del 12 de junio de 2009.

14 Unidad de Medida y Actualización, conforme al artículo tercero transitorio del decreto de reforma en materia de desindexación del salario mínimo, publicado en el Diario Oficial de la Federación el 27 de enero de 2016.

15 Al día de hoy, la libertad configurativa la encontramos en el artículo 109 de la Constitución federal, pues el texto constitucional en el cual se consigna la responsabilidad patrimonial fue trasladado del artículo 109 al 113, en virtud de las reformas en materia de combate a la corrupción, publicadas en el Diario Oficial de la Federación el 27 de mayo de 2015.

16 Algunos autores sostienen que daño y lesión no son dos expresiones equivalentes. "Toda lesión implicaría un daño, pero no todo daño sería lesión”. Al respecto, el Tribunal Supremo de España, en sentencia del 24 de febrero de 2004 (rec. 10869/1998) se ha pronunciado: "Si bien toda lesión es integrante de un daño y perjuicio no todo daño y perjuicio es constitutivo de una lesión... pues esa antijuridicidad o licitud sólo se produce cuando el afectado no hubiera tenido la obligación de soportar el daño o perjuicio y ese deber de soportar el daño o el perjuicio sufrido se da en los supuestos en que la ley y el grupo normativo de ella derivado justifican dichos detrimentos de un modo expreso o implícito". Cfr. Manzanares Samaniego, José Luis, La responsabilidad patrimonial por el funcionamiento de la administración de justicia, Madrid, La Ley, 2012, pp. 247 y 248. 


\section{Pronunciamiento de la Suprema Corte: LOS LÍMITES PREVISTOS EN LA INDEMNIZACIÓN POR DAÑO MORAL SON INCONSTITUCIONALES}

Sin embargo, ante tal imperativo, la Suprema Corte de Justicia de la Nación se ha pronunciado por la inconstitucionalidad de dicho tope máximo, sustentado en el argumento consistente en que si bien la existencia de límites a las indemnizaciones de los daños causados por el Estado es un objetivo cubierto por la Constitución general de la República (hoy en día a través del artículo 109), la fijación del tope máximo no constituye una medida adecuada, porque ni garantiza por sí misma que los abusos no se den ni resulta necesaria para evitarlos, no siendo lo suficientemente ajustada a los fines que pretende conseguir, sino que, por el contrario, en algunos casos puede ocasionar limitaciones irrazonables al derecho a ser indemnizado, además de que contraviene las obligaciones internacionales suscritas por el Estado mexicano, y podría plantear posibles problemas para cumplir con lo dispuesto por la Corte Interamericana y con las recomendaciones de la Comisión Interamericana en materia de reparación del daño. ${ }^{17}$

El más alto tribunal en tesis diversa, reiteró que el establecimiento de un tope máximo a las indemnizaciones a que puede ser condenado el Estado por daño moral no es en sí mismo una garantía contra los reclamos injustificados y las indemnizaciones excesivas, y puede entrar en tensión con los objetivos destacados en la exposición de motivos de la ley de la materia: cumplir con un imperativo de justicia, fortalecer el Estado de derecho, elevar la calidad de los servicios públicos, y restablecer la confianza que el Estado merece a los gobernados. Por lo tanto, si el cálculo del monto está disciplinado por el tope máximo establecido en la LFRPE, "habrá daños desiguales que serán tratados de la misma manera, y los particualres deberán asumir el costo que supere el tope máximo, lo cual no sólo impedirá la reparación integral de la violación sufrida, sino que le permitirá al Estado no asumir parte de las consecuencias de los daños que causa". ${ }^{18}$

17 Tesis 1a. CLIV/2009, Semanario Judicial de la Federación y su Gaceta, Novena Época, t. XXX, septiembre de 2009, p. 454.

18 Tesis 1a. CLVI/2009, Semanario Judicial de la Federación y su Gaceta, Novena Época, t. XXX, septiembre de 2009, p. 456.

Esta obra está bajo una Licencia Creative Commons Atribución-NoComercial-SinDerivar 4.0 Internacional, IIJ-UNAM. 
Si bien los derechos constitucionales no son absolutos y admiten restricciones, éstas no deben ser desprorcionadas ni arbitrarias, y por lo tanto, para justificar una restricción a un derecho constitucional, el tribunal ha determinado que la medida legislativa debe superar tres pasos:

1) Debe ser admisible constitucionalmente; esto es, debe introducirse para la consecución de un objetivo contemplado en la Constitución.

2) Debe ser una medida idónea, lo que implica que la restricción debe ser necesaria para la consecución del fin inicialmente propuesto, $y$

3) Debe ser proporcional respecto a la afectación que hace en otros bienes o intereses constitucionales. ${ }^{19}$

En tales circunstancias, la Primera Sala del más alto tribunal concluyó que no obstante la restricción legislativa cumplió el primer requisito, no se actualizó tal cumplimiento en el segundo, toda vez que el límite establecido en la norma no es el instrumentalmente idóneo para lograr que se erradique la realidad de los reclamos injustificados ni impide que se emitan indemnizaciones excesivas, aunado a que tales fines se cumplen adecuadamente con otras dos medidas en la ley: 1) la estructura de procedencia de los reclamos que delimitan el trámite jurídico de las peticiones, y 2) los criterios individualizadores de las indemnizaciones que vinculan a la autoridad aplicadora para determinar indmenizaciones justas y proporcionales. ${ }^{20}$

Estamos de acuerdo con el criterio adoptado por el tribunal, en el sentido de que no era suficiente que el legislador expusiera que el límite establecido por el artículo 14, fracción II, segundo párrafo, de la LFRPE, buscara evitar reclamos injustificados e indemnizaciones excesivas, pues con ello se cumplió únicamente con un requisito puramente formal, declarativo, que al cotejarse con el segundo requisito de análisis para justificar la restricción a un derecho constitucional se concluyó que "no era instrumentalmente idóneo para erradicar las conductas antes descritas"; en otras palabras, no existe correspondencia entre el objetivo aducido por el legislador ordina-

19 Tesis 1a./J. 2/2012, Semanario Judicial de la Federación y su Gaceta, Décima Época, t. I, febrero de 2012, p. 533.

20 Amparo en revisión 75/2009 resuelto por la Primera Sala de la Suprema Corte de Justicia de la Nación (SCJN), quejosas: Blanca Delia Rentería Torres y otra, fecha: 18 de marzo de 2009. Mayoría de cuatro votos. Disidente: José de Jesús Gudiño Pelayo. Ponente: José Ramón Cossío Díaz. Secretaria: Francisca María Pou Giménez, pp. II y III. 


\section{rio y la medida decretada, consistente en limitar el monto indemnizatorio a cargo del Estado. ${ }^{21}$}

21 De importancia son los argumentos esgrimidos por la Primera Sala de la SCJN para arribar a esta determinación, en los cuales se tomaron en consideración los diversos por esa Primera Sala al resolver el amparo en revisión 903/2008, donde se interpretó el derecho de las personas contenido en el artículo 113 constitucional, enfatizando que la indemnización derivada de la actividad administrativa irregular del Estado es un derecho constitucional sustantivo. Por tanto, la interpretación del artículo 113, segundo párrafo, de la Constitución federal, debe realizarse teniendo en cuenta que el citado precepto pone el énfasis de su regulación en "el derecho de los particulares de obtener una indemnización por la actividad administrativa irregular del Estado"; y, por lo tanto, la consecuencia normativa que tiene el precepto constitucional, no es la delimitación de esferas competenciales concretas, sino aquella que impone de manera principal una norma constitucional que establece un derecho: consagrar una prerrogativa que, por una parte, se establece como la obligación de éstas de encauzar sus potestades públicas, entre ellas la de configuración normativa, para asegurar que sus titulares disfruten la totalidad de la extensión del derecho constitucional garantizado.

Continuando con el desarrollo de su resolución, la Sala precisó que el derecho a una indemnización por la actividad administrativa irregular del Estado tiene un ámbito material propio, que no puede ser limitado por el legislador ordinario al desplegar sus facultades de creación normativa. Por lo tanto, en el contexto legal que regula la responsabilidad patrimonial del Estado, se desprende que existen medidas que son suficientes por sí mismas para evitar la interposición de reclamos injustificados y la existencia de indemnizaciones excesivas, que se vinculan más con la estructura general del régimen de responsabilidad patrimonial del Estado, que con el límite máximo de las indemnizaciones a que se puede condenar a éste. En tal orden de ideas, los "reclamos injustificados" como las "indemnizaciones excesivas" son dos aspectos "cuya supresión, se logra a través de la regulación de los rasgos estructurantes del régimen de responsabilidad patrimonial del Estado, cuyos resultados dependen de las facultades de las autoridades encargadas de su aplicación y no de la conducta espontánea de los particulares". En otras palabras, si llegaran a existir indemnizaciones excesivas no es por una falta de un límite máximo, sino porque "no existe un esquema de criterios individualizadores que vinculen a la autoridad a decretar una indemnización proporcional y justa".

Finalmente, cabe destacar que se precisó que la cantidad de la indemnización en cumplimiento del artículo 12 de la Ley Federal de Responsabilidad Patrimonial del Estado se debe determinar no en función de la capacidad económica del sujeto actor, sino de acuerdo la naturaleza del daño ocasionado, el resultado de la valoración de los derechos lesionados y el grado de responsabilidad del sujeto responsable. En tal virtud "se considerará que las indemnizaciones no son excesivas si, por una parte, se atiende a la compensación del daño creado y, por el otro, al grado de causalidad real de la actividad administrativa irregular del Estado; esto es, en función del grado de responsabilidad del sujeto responsable y la naturaleza de los derechos lesionados. El daño causado es el que determina la reparación, nunca un monto prefijado puede establecer de manera previa la afectación máxima que se puede sufrir". Al respecto, véase el amparo en revisión 75/2009 resuelto por la Primera Sala de la SCJN, quejosas: Blanca Delia Rentería Torres y otra, 


\section{LÍMITES IDÓNEOS PARA RESTRINGIR RECLAMOS INJUSTIFICADOS}

En concordancia con lo expuesto por la Sala en el amparo en revisión 75/2009, la LFRPE establece límites idóneos que restringen las posibilidades de existencia de reclamos injustificados e indemnizaciones excesivas, con el fin de evitar consecuencias perjudiciales en las arcas del Estado:

1. Límites internos, ${ }^{22}$ contenidos en el artículo 4 , son aquellos requisitos relacionados con la estructura del régimen de responsabilidad; esto es, que para poder acceder a la indemnización correspondiente, debe acreditarse que el daño causado por la actividad administrativa irregular del Estado sea real, evaluable en dinero, individualizado en una o varias personas, desigual al que pudiera afectar al común de la población, e imputable al Estado. En consecuencia, al no acreditarse alguno de los requisitos anteriores, el particular no podrá acceder a la reparación o compensación pretendida; siendo éstos elementos un medio de control contra los reclamos injustificados.

2. Límites indemnizatorios, tienen su origen en el artículo 14, fracción II, primer párrafo de la LFRPE, misma que a su vez remite a los criterios establecidos en el Código Civil Federal señalados en su artículo 1916, que en su párrafo cuarto establece que el monto de la indemnización lo determinará el juez tomando en cuenta los derechos lesionados, el grado de responsabilidad, la situación económica del responsable y la de la víctima, así como las demás circunstancias del caso. Dicho límite tiene como finalidad evitar la determinación de indemnizaciones excesivas. ${ }^{23}$

fecha: 18 de marzo de 2009. Mayoría de cuatro votos. Disidente: José de Jesús Gudiño Pelayo. Ponente: José Ramón Cossío Díaz. Secretaria: Francisca María Pou Giménez.

22 Amparo en revisión 75/2009, resuelto por la Primera Sala de la Suprema Corte de Justicia de la Nación, p. 32.

23 “...Así, el daño causado es el que determina la naturaleza y el monto de la indemnización, de forma que las reparaciones no pueden implicar enriquecimiento ni empobrecimiento para la víctima o sus sucesores; además, no se pretende que la responsabilidad sea excesiva, ya que debe subordinarse a requisitos cualitativos. Por otro lado, una indemnización será excesiva cuando exceda del monto suficiente para compensar a la víctima...". Tesis 1a./J. 31/2017, Gaceta del Semanario Judicial de la Federación, Décima Época, t. I, abril de 2017, p. 752. 
3. Límites excepcionales,${ }^{24}$ contenidos en el artículo 3, son las excepciones al derecho de ser inmdenizado, claramente identificadas por el legislador en dicha porción normativa, y de actualizarse alguna de ellas, el reclamante no tendrá derecho a acceder a la reparación establecida en la Ley, siendo éstas: los casos fortuitos y de fuerza mayor; los daños y perjuicios que no sean consecuencia de la actividad administrativa irregular del Estado; los hechos y circunstancias que no se hubieran podido prever o evitar según el estado de los conocimientos de la ciencia o técnica existentes en el momento de su acaecimiento; y cuando el solicitante de la indemnización sea el único causante del daño. Dicho límite tiene como finalidad evitar que prosperen los reclamos injustificados, así como las indemnizaciones excesivas, entendidas éstas como el resarcimiento que excede del monto suficiente para compenzar a la víctima; o bien, en este caso, cualquier resarcimiento cuyo origen derive de un daño que no es imputable al Estado.

4. Límites presupuestarios, ${ }^{25}$ contenidos en los artículos 5,8 y 11 , prevén las circunstancias mediante las cuales al haberse decretado a favor del gobernado el pago de una indemnización por la actividad administrativa irregular del Estado, éste podrá omitir (total o parcialmente) el cumplimiento de cubrir tal indemnización si en el ejercicio fiscal en el cual nace la obligatoriedad de resarcir el daño, no existe la disponibilidad presupuestaria suficiente; ${ }^{26}$ ello con la finalidad de no afectar el cumplimiento de los objetivos de los programas aprobados en el Presupuesto de Egresos de la Federación; sin que signifique de forma alguna que el sujeto obligado quede excento de reparar el daño, pues de la interpretación del texto nor-

24 Los hemos identificado con esta denominación, toda vez que acorde a la redacción del legislador ordinario, constituyen de forma expresa "la excepción a la regla" de la prerrogativa constitucional; no obstante la existencia de otros límites y excepciones contenidos de forma implícita en el texto normativo.

25 Lozano Díez, José Antonio, op. cit., p. 19.

26 Ello no significa que la disponibilidad presupuestaria dependerá del arbitrio del Estado, pues debemos recordar que el artículo único transitorio del decreto de reforma al artículo 113 publicado el 14 de junio de 2002 en el Diario Oficial de la Federación, establece la obligatoriedad de la Federación de incluir en sus respectivos presupuestos, una partida para hacer frente a su responsabilidad patrimonial. Por lo tanto, la disponibilidad presupuestaria dependerá de la existencia suficiente o no de recursos en la partida de "responsabilidad patrimonial", y no de los diversos compromisos a los que tenga que hacer frente la Federación; esto, pues al quedar delimitados los recursos destinados a cubrir obligaciones de carácter patrimonial, no se afecta el cumplimiento de los programas previamente presupuestados en las partidas respectivas. 
mativo, se desprende que deberá progamarse para el ejercicio inmediato posterior el monto destinado a cubrir la indemnización correspondiente. ${ }^{27}$

5. Límites disuasorios ${ }^{28}$ penales, contenidos en el artículo 10 , se actualizan cuando los entes públicos denuncien ante el Ministerio Público a una persona que haya participado directa o indirectamente, coadyuvado, asistido o simulado la producción de daños, con el propósito de acreditar indebidamente la responsabilidad patrimonial del Estado, u obtener alguna indemnización por ello.

Atendiendo a lo antes expuesto, es evidente que la LFRPE cuenta con una serie de medidas tendientes a inhibir reclamos e indemnizaciones improcedentes, congruentes con una debida reglamentación de la institución, que dispone medios de prueba causal, legal y técnicos rigurosos, sin que hipertrofie la actividad de la administración pública ni genere mayores obligaciones que las que tienen los servidores públicos. No se pretende generar una cultura del reclamo, sino controlar y propiciar la elevación progresiva de la calidad de los servicios públicos, fomentando así una cultura de la responsabilidad. ${ }^{29}$

\section{MOTIVACIONES PARA LIMITAR LAS INDEMNIZACIONES EN MATERIA DE RESPONSABILIDAD PATRIMONIAL}

Los elementos de control contenidos en la LFRPE hacen que al calzar a la institución con la previsión de un monto máximo a erogar por parte del

27 Al respecto, José Antonio Lozano Díez señala que las disposiciones relacionadas con cargo a las partidas presupuestales dejan al particular en cierto estado de indefensión, ya que tienen que esperar a que existan los recursos presupuestarios suficientes para que el Estado pueda resarcir el daño; y si el Estado ha tenido un comportamiento ineficiente en ejercicios fiscales anteriores, y por lo mismo deudas más antiguas por este concepto, su espera puede ser demasiado larga, lo que va en contra de la idea neoconstitucional de derechos humanos adoptada en 2011, que coloca al principio pro homine como de interpretación preponderante. Lozano Díez, José Antonio, op. cit., p. 20.

28 La idea principal de este término ha sido tomada de Mabel Ivanega, precisando que la autora lo aplica en el contexto de las normas que tienden a evitar el actuar en forma irregular de los agentes públicos. Ivanega, Miriam Mabel, "De las consecuencias de la responsabilidad estatal. Dos supuestos: la responsabilidad de los funcionarios públicos y la limitación de recursos públicos”, en Rodriguez-Arana Muñoz, Jaime et al. (coords.), La responsabilidad patrimonial de la administración pública, México, Espress, 2014, t. II, pp. 487-504.

29 Castro Estrada, Álvaro, Nueva garantía constitucional. La responsabilidad patrimonial del Estado, México, Porrúa, 2005, pp. 120 y 121. 
Estado por concepto de reparación de daños y perjuicios sea injustificado; desprendiéndose que dicho límite coincida en mayor medida con el temor de que pudieran verse afectadas de manera importante las arcas públicas; cuando, por el contrario, dicho temor puede superarse con un tratamiento riguroso de la institución que logre fortalecer el Estado de derecho, la justicia y la seguridad jurídica, que es igual a libertad individual y justicia para la comunidad y para cada uno de sus integrantes. ${ }^{30}$ Tal aserto tiene su origen en la experiencia comparada, pues en palabras de Eduardo García de Enterría, catedrático de derecho administrativo e impulsor de la responsabilidad patrimonial del Estado en España, desde 1954, escribió que hasta antes de esa fecha

...el artículo 1903 del Código Civil de 1889 prohibía esa responsabilidad, prohibición que se justificaba de hecho en el temor de que su reconocimiento pudiese dar lugar a una sangría de las finanzas estatales. Más de cuarenta años después, cuando la responsabilidad del Estado ha pasado a desenvolverse con plena normalidad en nuestra práctica administrativa y en la jurisprudencia de nuestros Tribunales, ese temor se ha revelado poco fundado. Un tratamiento rigurosamente técnico de la institución, a lo que conduce, más bien, es a una depuración efectiva de la acción administrativa que no necesita, para ser eficaz, ir dejando a su paso un reguero de daños ocasionales repartidos arbitrariamente entre las diferentes personas de la comunidad de Derecho. ${ }^{31}$

\section{ANÁLISIS DEL VOTO DISIDENTE DEL MINISTRO GUDIÑO PELAYO EN EL AMPARO EN REVISIÓN 75/2009}

La pertinencia de este análisis es tal, pues no obstante el pronunciamiento de la Primera Sala de la Suprema Corte de Justicia de la Nación (SCJN), el texo que establece un límite a la reparación patrimonial - en consecuencia impone un límite injustificado a un derecho sustantivo - continúa vigente, y genera el riesgo de que la autoridad encargada de sustanciar el trámite de indemnización, por desconocimiento o conveniencia, se ciña a lo preceptuado por el segundo párrafo, fracción II, del artículo 14 de la norma señalada, y si bien el particular afectado muy probablemente obtenga un pronunciamento favorable a través de los diversos medios de

\footnotetext{
30 Ibidem, p. 119.

31 Ibidem, pp. 119 y 120.
} 
impugnación, aparte de los gastos que tendría que erogar para ser patrocinado legalmente ante las instancias respectivas, ${ }^{32}$ dicha situación actualizaría una reiterada y sistemática violación al principio de impartición de justicia pronta y expedita previsto en el artículo 17 constitucional, lo cual podría remediarse, tratándose del monto máximo de indemnización, con la derogación de tal porción normativa, en cumplimiento a la obligación dispuesta en el artículo 1o. constitucional:

Todas las autoridades, en el ámbito de sus competencias, tienen la obligación de promover, respetar, proteger y garantizar los derechos humanos de conformidad con los principios de universalidad, interdependencia, indivisibilidad y progresividad. En consecuencia, el Estado deberá prevenir, investigar, sancionar y reparar las violaciones a los derechos humanos, en los términos que establezca la ley.

Se insiste en la inconveniencia de la vigencia del texto limitativo en el monto de la reparación por daño moral, en el sentido de que la autoridad aplicadora, aun interpretando la norma constitucional en ejercicio del control difuso, ${ }^{33}$ podría validar dicho precepto jurídico por considerarlo acorde a la Constitución federal.

Lo anterior cobra relevancia ante el hecho de que a través del voto particular formulado por el entonces ministro José de Jesús Gudiño Pelayo, se tiene un antecedente y constancia de lo que los entes públicos, al tramitar una reclamación de responsabilidad patrimonial — aunado al desconocimiento de la norma para interpretarla y aplicarla -34 podrían considerar totalmente válido y constitucional, precisamente por la redacción de la norma fundamental. En este respecto, el jurista señalado consideró pertinente que la pregunta relevante para efectos de establecer si la regla del artículo 14, fracción II, es constitucional o inconstitucional, no es la que se plantea en el proyecto, sino la que se enuncia a continuación: ¿puede dejarse abierta, sin fijación de montos máximos, la indemnización a que puede ser condenado el Estado?

32 Recurso de revisión ante la autoridad responsable, con carácter optativo; juicio contencioso-administrativo ante el Tribunal Federal de Justicia Fiscal y Administrativa; juicio de amparo a la par de la revisión fiscal; amparo directo en revisión. Acosta García, Cristian Miguel, op. cit., p. 201.

33 Ibidem, p. 161.

34 Ibidem, p. 187.

Esta obra está bajo una Licencia Creative Commons

Atribución-NoComercial-SinDerivar 4.0 Internacional, IIJ-UNAM. 
Continúa reflexionando el ministro, que lo que está en tela de juicio es determinar si el derecho a la indemnización, en el caso específico del daño moral, puede dejarse abierto y sólo en manos de la discrecionalidad del juez, a lo que responde que no, aduciendo que el legislador puede válidamente establecer límites al monto de la indemnización, pues así se lo autoriza la parte final del artículo 113 constitucional: "Los particulares tendrán derecho a una indemnización conforme a las bases, límites y procedimientos que establezcan las leyes"; y la razón de esto, argumenta, está en que el Estado, si bien es solvente para todos los efectos legales, "no puede ver menoscabadas sus arcas con base en condenas excesivas, fijadas únicamente al arbitrio del juez", y por lo tanto, señala, es necesario poner un límite al poder discrecional del juzgador en este ámbito. ${ }^{35}$

Es claro que el temor de ver menoscabadas las arcas del Estado con la aplicación de la institución continúa vigente, y es dicha percepción lo que encauzaría a la entidad respectiva a aplicar la norma que impone un monto máximo a la reparación por daño moral; ello considerando el beneficio que representaría a la entidad respectiva si se está ante la presencia de afectaciones morales, que aplicando los parámetros establecidos en el artículo 1916 del Código Civil Federal ${ }^{36}$ pudiera ver notablemente rebasado el límite autorizado por el legislador federal.

Afortunadamente, y no obstante la vigencia del precepto limitario, ya es obligatorio el criterio de la Suprema Corte en el sentido de que limitar la responsabilidad fijando un techo cuantitativo implica marginar las circunstancias concretas del caso, el valor real de la reparación o de la salud deteriorada; esto es, una indemnización es injusta cuando se le limita con topes o tarifas, y en lugar de ser el juez quien la cuantifique justa y equitativamente con base en criterios de razonabilidad, al ser quien conoce las particularidades del caso, es el legislador quien, arbitrariamente, fija montos indemnizatorios, al margen del caso y de su realidad. Dicha obligatoriedad deriva de la circunstancia de que tal criterio es de rango

\footnotetext{
35 Voto particular que formula el ministro José de Jesús Gudiño Pelayo en el amparo en revisión 75/2009, interpuesto por Blanca Delia Renterría Torres y otra, pp. 5 y 6.

36 "El monto de la indemnización lo determinará el juez tomando en cuenta los derechos lesionados, el grado de responsabilidad, la situación económica del responsable, y la de la víctima, así como las demás circunstancias del caso". Código Civil Federal publicado en el Diario Oficial de la Federación en cuatro partes los días 26 de mayo, 14 de julio, 3 y 31 de agosto de 1928, última reforma publicada el 3 de junio de 2019.
} 
jurisprudencial, ${ }^{37}$ visibe en la tesis de rubro "Derecho fundamental a una reparación integral o justa indemnización. Su concepto y alcance". ${ }^{8}$

\author{
VIII. PROPUESTA: PREGUNTA LÓGICO-JURÍDICA \\ PARA ARRIBAR A LA CONCLUSIÓN DE UNA INDEMNIZACIÓN \\ JUSTA POR DAÑO MORAL
}

\begin{abstract}
¿Puede el particular afectado percibir una cuantía menor por concepto de indemnización en proporción al daño causado por el Estado? Dicha pregunta se formula en contraposición a la diversa realizada en el voto particular del entonces ministro Gudiño Pelayo: “¿Puede dejarse abierta, sin fijación de montos máximos, la indemnización a que puede ser condenado el Estado?". La respuesta a aquélla se encuentra implícita en la resolución del ya citado amparo en revisión 75/2009, cuando la Primera Sala adujo lo siguiente: "El daño causado es el que determina la reparación, nunca un monto prefijado puede establecer de manera previa la afectación máxima que se puede sufrir". ${ }^{39}$ De igual forma, al emitir la tesis CLVI/2009 determinó:
\end{abstract}

si el cálculo del monto está disciplinado no sólo por la entidad del daño y el grado de responsabilidad del sujeto que lo causa... sino también por el tope monetario máximo establecido en la fracción II del artículo 14 de la Ley Federal de Responsabilidad Patrimonial del Estado, habrá daños desiguales que serán tratados de la misma manera. En esta categoría de casos, los particulares deberán asumir el costo que supere el tope máximo, lo cual no sólo impedirá la reparación integral de la violación sufrida en sus derechos, sino que le permitirá al Estado no asumir parte de las consecuencias de los daños que causa, dejándolo sin los incentivos necesarios para adoptar medidas que eliminen o aminoren la mala calidad de los servicios públicos.

Finalmente, el citado criterio jurisprudencial 1a./J. 31/2017 reza que el derecho moderno de daños mira la naturaleza y extensión del daño a las víctimas y no a los victimarios, y así, el

37 Artículo 217 de la Ley de Amparo, Reglamentaria de los Artículos 103 y 107 de la Constitución Política de los Estados Unidos Mexicanos, publicada en el Diario Oficial de la Federación el 2 de abril de 2013, última reforma publicada el 15 de junio de 2018.

38 Tesis 1a./J. 31/2017, Gaceta del Semanario Judicial de la Federación, Décima Época, t. I, abril de 2017, p. 752.

39 Amparo en revisión 75/2009, resuelto por la Primera Sala de la Suprema Corte de Justicia de la Nación, p. 63. 
daño causado es el que determina la naturaleza y el monto de la indemnización, de forma que las reparaciones no pueden implicar enriquecimiento ni empobrecimiento para la víctima, pues no se pretende que la responsabilidad sea excesiva, ya que debe subordinarse a requisitos cualitativos, en el entenido que una indemnización será excesiva cuando exceda del monto suficiente para compensar a la víctima.

En el mismo sentido se ha pronunciado la doctrina, al referir que “...el fundamento es el daño en sí mismo, por ser antijurídico, ya que quebranta los principios de equidad, igualdad y bien común, por lo cual, cualquier conducta cometida por los servidores públicos, normal o anormal, culposa o no, lícita o ilícita, debe ser respondida por el Estado...", ${ }^{40}$ pues "no puede haber responsabilidad sin la existencia de un daño, el cual es la esencia de la responsabilidad...". ${ }^{41}$

Así, dada la trascendencia del instituto de responsabilidad patrimonial, elevado a garantía constitucional, la lesión por falta de reparación del daño "no será a nivel patrimonial, sino al de derechos fundamentales". ${ }^{42}$

De esta manera, si bien indemnizaciones demasiado excesivas pueden provocar la paralización de una actividad o de un sector, de manera que es necesario acomodar su cuantía al nivel económico de un país, ello no es base ni justificación alguna para que no exista "el equilibrio entre compensación adecuada y la efectividad y viabilidad de los mecanismos de reparación". ${ }^{43}$

A nuestro criterio, y ante lo antes expuesto, la pregunta anterior: ¿puede el particular afectado percibir una cuantía menor por concepto de indemnización en proporción al daño causado por el Estado?, cobra revelencia ante la vigencia, insistimos, del inconstitucional límite dispuesto en el artículo 14, fracción II, de la LFRPE; y, por lo tanto, consideramos, es uno de los enunciados que podría formularse la autoridad encargada de determinar el monto indemnizatorio por la reparación del daño moral, para arribar a la conclusión de fijar una compensación justa, subordinada a criterios cualitativos, sin que ello se traduzca en que la resolución que tenga como base tales criterios esté resarciendo de forma excesiva al particular afectado.

\footnotetext{
40 Murillo Morales, Jaime, Responsabilidad patrimonial de la administración de justicia, México, Ubijus, 2014, p. 111.

41 Ibidem, p. 117.

42 Ibidem, p. 112.

43 Ibidem, p. 147.
} 
Estamos conscientes de que la Suprema Corte ya se ha pronunciado por tal inconstitucionalidad, y que las mismas resoluciones constituyen herramientas obligatorias suficientes que deben llevar a la entidad facultada de resolver la cantidad compensatoria, a inclinarse por una decisión justa y proporcional al daño causado por el Estado. Sin embargo, la administración pública no cuenta con la preparación suficiente, ${ }^{44} \mathrm{o}$ bien desconoce el instituto de responsabildad patrimonial, lo cual puede traducirse en que la autoridad correspondiente opte por la aplicación íntegra del artículo 14, fracción II, de la LFRPE.

Por lo tanto, aun ante el desconocimiento del sistema de responsabilidad patrimonial, y en consecuencia, de los pronunciamientos de la Corte mexicana, el enunciado propuesto en forma de pregunta básica podría llevar al resolutor del caso respectivo a construir una resolución adecuada inaplicando la inconstitucional porción normativa del numeral señalado, e inclusive al conocimiento de los trascendentes pronunciamentos del alto tribunal, evitando determinaciones contrarias a derecho, que sólo generarían mayores cargas al gobernado en la búsqueda de la anulación de un resolución de tales características.

\section{Criterios ReCientes de la Suprema Corte DE JUSTICIA DE LA NACIÓN}

Uno de los criterios adoptados recientemente por la $\mathrm{SCJN}^{45}$ consiste en precisar las reglas cuando se tramiten dos vías distintas para reclamar

\footnotetext{
44 Castro Estrada señalaba: "En forma complementaria a los programas de desarrollo administrativo que deberán diseñarse a fin de preparar a la Administración Pública para este nuevo reto, será pertinente pensar en los ajustes... que tengan como finalidad establecer los procedimientos internos y las unidades administrativas que tendrán competencia para sustanciar las solicitudes... de reclamación; de manera tal que la desorganización o el desconcierto no se presenten al momento de entrar en vigor la reforma constitucional... La relevancia de estas acciones de preparación previa es manifiesta si se toma en cuenta que el el retraso o la desatención indebida de un reclamo de esta naturaleza podría traer consigo reclamos adicionales, en tanto que tal desatención conlleve nuevas afectaciones patrimoniales para el particular reclamente.

El punto de los presupuestos necesarios que deberán destinarse a organizar y establecer órganos nuevos $u$ ampliar los existentes... es, indudablemente, otro de los rubros indispensables que no pueden desatenderse so pena de hacer nugatoria la nueva garantía constitucional" [el resaltado es nuestro]. Castro Estrada, Álvaro, Nueva garantía constitucional..., cit., p. 246.

45 Tesis: 2a. XIX/2018 (10a.), Gaceta del Semanario Judicial de la Federación, Décima Época, t. II, marzo de 2018, p. 1439.
} 
indemnización por responsabilidad patrimonial, específicamente por las vías administrativa y jurisdiccional. El más alto tribunal separa los montos pecuniarios respectivos; sin embargo, al estar destinados para los mismos efectos, es decir, la reparación por la actividad irregular del Estado, determina que debe haber compensación.

Por una parte, y en protección de los intereses del gobernado, dispone que la autoridad que conozca de los casos, en el supuesto de acreditarse la responsabilidad patrimonial del Estado, entre al estudio de fondo y calcule la indemnización integral debida, sin que de un análisis preliminar pueda darse por satisfecha la repración integral del daño por el simple hecho de haberse entregado una indemnización previa, producto del trámite de una queja adsministrativa.

Sin embargo, por otra parte, y en aras del Estado, da plena validez a la indemnización decretada por la autoridad administrativa, por lo que de existir un pago por un concepto indemnizatorio obtenido en dicha vía y por los mismos hechos, la autoridad jurisdiccional deberá restarlo del monto de la reparación integral a pagar.

De igual forma, encontramos con criterio diverso, ${ }^{46}$ en el que la SCJN identificó un límite a la indemnización, distinto al tratado en el presente, pero que es importante destacar atendiendo a la protección federal que debe intervenir ante ciertas carencias respecto a la protección de la persona, plasmadas por el legislador ordinario, siendo el artículo controvertido, el 14, fracción I, inciso a), de la LFRPE, en razón de que

El precepto citado señala que los montos de las indemnizaciones en el caso de daños personales se calcularán conforme a lo dispuesto para riesgos de trabajo en la Ley Federal del Trabajo, lo que limita por consecuencia la posibilidad de indemnización a las personas que tengan una relación laboral... pues al utilizar el salario mínimo como parámetro de reparación económica, excluye los casos de aquellas personas que no perciben uno. Así, conforme al principio de igualdad, pesaba sobre el legislador el deber adicional de proteger la situación especial de los menores de 15 años... precisamente en que los daños derivados de un accidente o enfermedad no pueden calcularse... en función del perjuicio que sufrirán al dejar de trabajar, ya que existe una restricción constitucional que prohíbe cualquier tipo de trabajo de los menores de esa edad. Así... el artículo 14, fracción I, inciso a), de la Ley Federal de

46 Tesis: 2a. XXXI/2018 (10a.), Gaceta del Semanario Judicial de la Federación, Décima Época, t. I, abril de 2018, p. 861. 
Responsabilidad Patrimonial del Estado es inconstitucional al ser subinclusivo, porque excluye injustificadamente del acceso a una indemnización por daños personales, a individuos que se sitúan en condiciones iguales que otros respecto del daño producido por la actuación irregular del Estado, personas a las que, además, en atención a su situación especial por ser menores, tendría que haber protegido con mayor especialidad y alcance.

\section{Propuestas iniciales Versus texto CONSTITUCIONAL VIGENTE}

Tal como se señaló al inicio del presente, las propuestas iniciales de la institución incluían la proporcionalidad y equidad, ya en conjunto o alguna de ambas, con relación a la indemnización derivada de la lesión causada por el Estado. Sin embargo, respecto al monto por concepto de resarcimiento, el actual texto constitucional, en su artículo 109 precisa que "Los particulares tendrán derecho a una indemnización conforme a las bases, límites y procedimientos que establezcan las leyes".

Las razones de Castro Estrada para incluir dichas expresiones fueron las siguientes:

El sentido de la expresión proporcional y equitativa que aquí se usó fue el que tuvo en su origen, como criterio de justicia, y que permite dar un tratamiento igual a los iguales, y desigual a los desiguales. Se trata del criterio que yo he llamado de ponderación, en virtud del cual las indemnizaciones no deben ser iguales para todos, sino integrales para quienes menos ingresos tienen, y equitativas para quienes más ingresos perciben. Además, no considero que la indemnización proveniente de una actividad administrativa indebida deba ser la misma que una debida; la primera debe ser integral; y la segunda, equitativa (a pesar de que, en materia de responsabilidad objetiva, la conducta de los agentes públicos no es el dato relevante, sino la relación causa-efecto entre la actividad que se imputa al Estado y la lesión antijurídica ocasionada). En otras palabras, la intención de haber incluído la expresión proporcional y equitativa fue la de dar base constitucional a las indemnizaciones ponderadas o diferenciadas...

A pesar de lo dicho, considero que el razonamiento que se incluyó en el Dictamen de la H. Cámara de Diputados para prescindir de tal expresión, parece justificado, en cuanto a que, si bien en su expresión primigenia proporcional y equitativa era la de justicia, hoy la práctica impositiva fiscal le ha dado una significación técnica muy especializada para tales ámbitos 
(artícuo 31 fracción IV), por lo que se estima inconveniente su utilización en materia de responsabilidad patrimonial del Estado. Estoy de acuerdo en que todo aquello que pudiese generar alguna confusión debe omitirse, máxime que como dice el mencionado Dictamen: ' ...Por el sólo hecho de establecer que los particulares tendrán derecho a una indemnización, se implica que será justa, y, siendo consecuentes con su auténtico significado, que será proporcional y equitativa'. ${ }^{47}$

Podemos constatar que el sentido de la expresión proporcional y equitativa se usó como criterio de justicia en relación con las indemnizaciones a las que los particulares tuvieran derecho.

Cabe resaltar que el jurista en mención, si bien considera que el dato relevante en materia de responsabilidad objetiva es la relación causa-efecto y la lesión antijurídica, también se inclina por el criterio de que las indemnizaciones serán en razón del grado del ingreso que la víctima perciba, haciendo — el tratadista - hincapié en que las indemnizaciones no deben ser iguales para todos, y manifiesta su postura en que, inclusive, la indemnización proveniente de una actividad administrativa indebida no debe ser la misma que una debida.

Compartimos el criterio de justicia que el tratadista le da como sentido a la expresión proporcional y equitativa; sin embargo, nos apartamos del resto de los argumentos que a continuación se señalan, por las siguientes razones:

1. Respecto a la proporcionalidad y equidad, Castro Estrada señala: "Se trata del criterio que yo he llamado de ponderación, en virtud del cual las indemnizaciones no deben ser iguales para todos, sino integrales para quienes menos ingresos tienen, y equitativas para quienes más ingresos perciben".

Tal y como apuntamos en la nota 13 del presente, compartimos el criterio sentado en el amparo en revisión 75/2009, que establece:

cabe destacar que se precisó que la cantidad de la indemnización en cumplimiento del artículo 12 de la Ley Federal de Responsabilidad Patrimonial del Estado, se debe determinar no en función de la capacidad económica del sujeto actor, sino en función de la naturaleza del daño ocasionado, el resultado de la valoración de los derechos lesionados y el grado de responsabilidad

47 Ibidem, pp. 194 y 195. 
del sujeto responsable. En tal virtud, se considerará que las indemnizaciones no son excesivas si, por una parte, se atiende a la compensación del daño creado... El daño causado es el que determina la reparación...

En tal sentido, existe contraposición entre los argumentos:

- las indemnizaciones deben ser integrales para quienes menos ingresos tienen, y equitativas para quienes más ingresos perciben.

- la indemnización se debe determinar como resultado de la valoración de los derechos lesionados.

Reiteramos que nos inclinamos por el razonamiento de la SCJN, precisamente porque restituir o indemnizar a la víctima en proporción al daño causado, y no en función de su capacidad económica, pone de relieve la justicia que puede identificarse con el bien común y con los derechos humanos que ocupa la centralidad axiológica del derecho, ${ }^{48}$ además de que sería discriminatorio privar a las víctimas de la reparación integral derivado del artículo 63.1 de la Convención Americana sobre Derechos Humanos, únicamente por su capacidad económica (el tratadista en análisis limita las indemnizaciones integrales únicamente para quienes menos ingresos tienen).

De igual forma, el artículo 12 de la LFRPE dispone que "Las indemnizaciones corresponderán a la reparación integral del daño" sin acotarlas sólo a las personas de escasos recursos, porque, precisamente, atendiendo a la restitución del daño causado, propusimos la pregunta: “¿puede el particular afectado percibir una cuantía menor por concepto de indemnización en proporción al daño causado por el Estado?". Situación que correría el riesgo de actualizarse, de aplicar el criterio que la indemnización debe ser en función de la capacidad económica de la víctima; es decir, que si el afectado resulta ser una persona considerada dentro del grupo de "quienes más ingresos reciben”, la restitución podría ser menor en proporción al daño causado, toda vez que no se aplicaría la restitutio in integrum.

2. La responsabilidad patrimonial del Estado como garantía constitucional: tomando en consideración la definición de garantía constitucional

\footnotetext{
48 Vigo, Rodolfo Luis, Constitucionalización y judicialización del derecho, México, Porrúa-Universidad Panamericana, 2016, p. 28.

Esta obra está bajo una Licencia Creative Commons

Atribución-NoComercial-SinDerivar 4.0 Internacional, IIJ-UNAM.
} 
de Eréndira Salgado Ledezma, tenemos que "son instrumentos de naturaleza procesal cuya finalidad es la restauración del orden constitucional cuando éste ha sido desconocido o violado por los órganos de poder y los instrumentos protectores no fueron suficientes para lograr el respeto de la Constitución y la vigencia del Principio de Supremacía". ${ }^{9}$

Compartimos la idea de que la responsabilidad patrimonial del Estado podría ser una garantía que proteja la integridad patrimonial, o bien la integridad en general del ser humano en todos sus aspectos respecto de actos del Estado, tomando en consideración que no se constriñe únicamente a cuestiones patrimoniales, sino que también incluye las extrapatrimoniales.

Sin embargo, en lo referente al criterio de que la proporcionalidad y equidad pueden llevar a una solución justa para mantener íntegro el patrimonio, consideramos bastante la idea antes apuntada, consistente en que "la indemnización se debe determinar como resultado de la valoración de los derechos lesionados", pues con ello se pone de relieve el principio de justicia.

Lo anterior, pues tal como quedó apuntado, Castro Estrada señala: "si bien en su expresión primigenia proporcional y equitativa era la de justicia, hoy la práctica impositiva fiscal le ha dado una significación técnica muy especializada". En dicho tenor, consideramos que acudir a la valoración de los daños para determinar la indemnización resolvería el tema de la justicia antes que el criterio de proporcionalidad y equidad, sobre todo tomando en consideración el criterio jurisdiccional, ${ }^{50}$ que establece que la proporcionalidad y equidad, desarrollados a partir del enfoque fiscal, deben atender a la capacidad económica, y reitera el argumento de Castro Estrada: trato igual a los iguales y desigual a los desiguales, cuando, conforme al razonamiento que hemos venido sosteniendo, las condiciones y circunstancias económicas de la víctima no pueden determinar el grado, cuantía o nivel de reparación, sino lo hará el daño, y, por lo tanto, los alcances de la afectación sufrida por el individuo afectado.

49 "México" (sic), Enciclopedia Jurídica Online, José Luis Soberanes, voz: "Garantías constitucionales", disponible en: https://mexico.leyderecho.org/garantias-constitucionales/ (fecha de consulta: 28 de junio de 2019).

50 Tesis P. XLI/93, Gaceta del Semanario Judicial de la Federación, octava época, julio de 1993, p. 25. 


\section{PRESUNCIÓN DEL DAÑO MORAL EN EL CONSEJO DE ESTADO DE COLOMBIA}

El perjuicio moral puede ser definido como aquel que impacta la órbita interna del sujeto, concretamente su esfera emotivo-espiritual, que generalmente se manifiesta en forma de dolor, congoja, pesadumbre, aflicción, intranquilidad o cualquier forma de alteración emocional. Sin embargo, es importante precisar que la alteración emocional no puede ser patológica, pues de serlo se estaría frente a un daño a la salud de tipo psicológico. ${ }^{51}$

En el ordenamiento jurídico colombiano el daño moral se reconoció por la Corte Suprema de Justicia en la sentencia de casación el 21 de julio de 1922, y en la sustitutiva del 22 de agosto de 1924, proferidas en el caso Villaveces. En éstas, la Corte reconoció indemnización por daño moral a favor del señor Villaveces por haber sido violentada la bóveda donde se encontraban los restos de su esposa, que fueron arrojados a una fosa común. ${ }^{52}$

Respecto a la presunción por daño moral, el Consejo de Estado, en su sentencia 6750 del 17 de julio de 1992, estableció que aplica para los parientes hasta el segundo grado por consanguinidad y primero civil, ya sean ascendientes, descendientes o colaterales, ocupándose, en específico en dicha sentencia, de los hermanos. ${ }^{53}$ Es decir, basta demostrar el vínculo familiar en el grado de parentesco estipulado, para convertirse en titular de la indemnización respectiva por el dolor o aflicción causado por el daño inferido a la víctima directa.

Si bien en la sentencia no se especifica si tal presunción admite prueba en contrario, consideramos que atendiendo a cada caso particular habrá de admitirse prueba en contrario por la parte a quien no beneficie tal presunción; lo anterior, tomando en cuenta que en el ordenamiento colombiano, dentro de las presunciones legales, se distinguen las iuris tantum — que admiten prueba en contrario-y las presunciones iuris et de iure - que no admiten prueba en contrario- - tomando como fundamento el artículo 176 del Código de Procedimiento Civil, que establece que "las presunciones

51 Martínez Benavides, "Análisis de la presunción de daño moral que beneficia a ciertas víctimas indirectas en la jurisdicción contencioso administrativa colombiana", Revista Derecho del Estado, Bogotá, núm. 42, enero-abril de 2019, pp. 181-210.

52 Idem.

53 Sentencia 6750, del Consejo de Estado - Sala de lo Contencioso Administrativo-, sección tercera, 17 de julio de 1992, disponible en: https://2019.vlex.com/\#vid/355912926 (fecha de consulta: 29 de junio de 2019) 
establecidas por la ley serán procedentes siempre que los hechos en que se funden estén debidamente probados. El hecho se tendrá por cierto pero admitirá prueba en contrario cuando la ley lo autorice". ${ }^{54}$

En el país objeto de análisis son dos las posturas respecto de la exigencia probatoria por daño moral. La primera y más antigua en el tiempo sostiene que el daño moral no requiere de prueba, y la segunda defiende que el daño moral, al igual que cualquier otro tipo de daño, debe ser probado por quien pretenda su reparación, destacando que ambas posturas conviven en las posturas de los tribunales de justicia. ${ }^{55}$

\section{CONCLUSIONES}

De acuerdo con lo expuesto, compartimos los criterios analizados en el presente, emitidos por la SCJN, con relación a que el daño causado es el que determina la naturaleza y el monto de la indemnización, así como el grado de responsabilidad del sujeto que lo causa, por lo cual nos apartamos de la postura que sostiene que el monto resarcitorio se defina con base en los ingresos del víctima, sin que ello signifique que estos factores no deban ser tomados en cuenta al momento de cuantificar la indemnización, pero que, insistimos, el factor principal y preponderante lo será el daño causado, y en consecuencia, los alcances y efectos de éste.

En cuanto a que el tratadista compartió que la H. Cámara de Diputados prescindiera de la expresión primigenia proporcional y equitativa, atendiendo a que todo aquello que pudiera generar alguna confusión debe omitirse, estimamos que, no obstante apartarnos ciertos alcances que el tratadista apoya respecto a la proporcionalidad y equidad, hubiera sido más conveniente a la vigente de hoy en día: "Los particulares tendrán derecho a una indemnización conforme a las bases, límites y procedimientos que establezcan las leyes"; esto es, porque aunque no estemos convencidos de que el monto de la indemnización sea definido — principalmente — en razón de los ingresos de las víctimas, el criterio de justicia contenido en la expresión referida hubiera tenido mayor protección a nivel constitucional tratándose

54 Sentencia C-731/05 de la Sala Plena de la Corte Constitucional de la República de Colombia del 12 de julio de 2005, disponible en: http://www.corteconstitucional.gov.co/ relatoria/2005/c-731-05.htm (fecha de consulta: 29 de junio de 2019)

55 Cárdenas Villarreal, Hugo A. y Gonález Vergara, Paulina V., "Notas en torno a la prueba del daño moral: un intento de sistematización", Revista Facultad de Derecho y Ciencias Políticas, Bogotá, vol. 37, núm. 106, enero-junio 2007, pp. 213-237. 
de los bienes y derechos de los afectados, sin que se permitiera — no constitucionalmente - que el legislador ordinario emitiera normas contrarias al principio de justicia, porque si bien tal vez el efecto de la expresión límites no sea de causar confusión, sí permite — en principio - que aquél cuente con las facultades constitucionales para fijar los límites que considere con relación a la reparación y compensación del daño, generando el desatino que el límite fijado en la ley sea inconstitucional e injusto. Por lo tanto, y toda vez que el daño causado es el que determina la naturaleza y el monto de la indemnización, nos remitimos a la propuesta realizada, consistente en la formulación de la pregunta "¿puede el particular afectado percibir una cuantía menor por concepto de indemnización en proporción al daño causado por el Estado?", a partir de la cual, dada la sencillez del planteamiento, se puede realizar la reflexión en torno a los alcances de la reparación, pasando por el concepto de reparación integral, llegando al conocimiento de los pronunciamientos acerca de la inconsticionalidad del artículo 14, fracción II, de la LFRPE, tomando en cuenta que la corriente actual atempera la cuantía de la indemnización a "los modos valorativos convencionales utilizados por las jurisdicciones civil, penal y laboral". ${ }^{56}$

Finalmente, reconocemos que no obstante la declaración de inconstitucionalidad del artículo 14, fracción II, de la LFRPE, continúan los problemas e inconvenientes respecto de su aplicación; esto es, porque su contenido, al ser replicado por legislaciones locales, pone de relieve que las autoridades locales, aun el criterio objeto de análisis del presente, han pretendido aplicar a la letra los límites a la indemnización por daño por daño moral, lo que ha dado lugar a la emisión de criterios de inconstitucionalidad, a través de amparos directos interpuestos ante las autoridades jurisdiccionales federales. ${ }^{57}$

\section{BIBLIOGRAFÍA}

Acosta García, Cristian Miguel, Responsabilidad patrimonial del Estado. Teoría y casos prácticos, México, Novum.

56 Delgado Sancho, Carlos David, La responsabilidad patrimonial de las administraciones públicas, España, Gomylex, 2013, p. 63.

57 Tesis III.10.A.34 A (10a.), Gaceta del Semanario Judicial de la Federación, Décima Época, t. II, diciembre de 2016, p. 1854; tesis: XVI.1o.A.109 A (10a.), Gaceta del Semanario Judicial de la Federación, décima época, t. IV, octubre de 2016, p. 3084; tesis III.5o.A.12 A (10a.), Gaceta del Semanario Judicial de la Federación, décima época, t. III, abril de 2016, p. 2548. 
CAStro EstradA, Álvaro, Nueva garantía constitucional. La responsabilidad patrimonial del Estado, México, Porrúa, 2005.

CAstro Estrada, Álvaro, Responsabilidad patrimonial del Estado, México, Porrúa, 2006.

Delgado SANCHO, Carlos David, La responsabilidad patrimonial de las administraciones públicas, España, Gomylex, 2013.

MANZANARES SAMANIEGO, José Luis, La responsabilidad patrimonial por el funcionamiento de la administración de justicia, Madrid, La Ley, 2012.

MARTÍNEZ BENAVIDES, “Análisis de la presunción de daño moral que beneficia a ciertas víctimas indirectas en la jurisdicción contencioso administrativa colombiana", Revista Derecho del Estado, Bogotá, Universidad Externado de Colombia, núm. 42, enero-abril de 2019

Mendoza Martínez, Lucía Alejandra, La acción civil del daño moral, México, UNAM, Instituto de Investigaciones Jurídicas, 2014.

Murillo Morales, Jaime, Responsabilidad patrimonial de la administración de justicia, México, Ubijus, 2014.

PÉREZ FuENTES, Gisela María (coord.), Temas actuales de responsabilidad civil, México, Tirant lo Blanch, 2018.

RODRIGUEZ-ArANA MuÑOZ, Jaime et al. (coords.), t. I: La responsabilidad patrimonial de la administración pública, México, Espress, 2014.

RODRIGUEZ-ARANA MUÑOZ, Jaime et al. (coords.), t. II: La responsabilidad patrimonial de la administración pública, México, Espress, 2014.

SteIner, Christian y URIBE, Patricia, Convención Americana sobre Derechos Humanos comentada, México, Suprema Corte de Justicia de la Nación.

Oliva Gómez, Eduardo y Villa GuARDiola, Vera Judith, "Hacia un concepto interdisciplinario de la familia en la globalización", Justicia Juris, vol. 10, núm.1, enero-junio de 2014.

Vigo, Rodolfo Luis, Constitucionalización y judicialización del derecho, México, Porrúa-Universidad Panamericana, 2016.

Fecha de recepción: 28 de agosto de 2017.

Fecha de aceptación: 28 de mayo de 2019.

Esta obra está bajo una Licencia Creative Commons Atribución-NoComercial-SinDerivar 4.0 Internacional, IIJ-UNAM. 